Discurso e información. El estatuto del discurso de la información y el rol de los lectores en la coproducción de sentidos del discurso mediático

Alejandra Valentino, Claudia Fino

Apuntes de comunicación, educación y discurso (N. ${ }^{\circ}$ 2), e012, noviembre 2017

ISSN 2525-2046 | https://doi.org/10.24215/25252046e012

http://perio.unlp.edu.ar/ojs/index.php/apuntes

FPyCS | Universidad Nacional de La Plata

La Plata | Buenos Aires | Argentina

\title{
Disc urso e información El estatuto del disc urso de la información y el rol de los lectores en la coproducción de sentidos del disc urso mediático
}

\author{
Disc ourse and Information
}

The status of the discourse of information and the role of readers in the co-production of meanings of media disc ourse

Alejandra Valentino

a valentino@perio.unlp.edu.ar https:/ / orc id .org/0000-0003-0073-2183

\section{Claudia Fino}

claudiafino@yahoo.com.ar

https://orcid .org/0000-0003-1220-7204

\section{Centro de Investiga ción en Comunicación, Educación y Disc urso (COMEDI) \\ Facultad de Periodismo y Comunicación Social \\ Universidad Nacional de La Plata \\ Argentina}

\begin{abstract}
Resumen
El presente artículo esboza la propuesta de diseño teórico metodológico desarrollada en el marco de un proyecto de investigación que propone el análisis y la desnaturalización del discurso de la información inscripto en el discurso social. Se problematiza el rol de los lectores / espectadores como coproductores de la significación de los contenidos mediáticos a partir del estudio de los comentarios en diferentes portales digitales. El enfoque del discurso resitúa el modo de pensar estas formaciones ideológicas y destierra una manera de entender la información como aséptica y objetiva.
\end{abstract}

Palabras clave

discurso de la información, comentarios de lectores, construcción de sentidos

\section{Abstract}

This article outlines the theoretical and methodological design proposal developed within the framework of a research project that proposes the analysis and denaturing of the discourse of information inscribed in the social discourse. The role of readers / viewers as co-producers of the meaning of media content is analyzed from the study of the comments in different digital portals linked. The focus of the discourse redefines the way of thinking these ideological formations and banishes a way of understanding the information as aseptic and objective.

Keywords

information discourse, comments from readers, construction of sense 


\title{
Disc urso e información \\ E estatuto del discurso de la información y el rol \\ de los lec tores en la coproducción de sentidos \\ del disc urso mediático
}

\author{
PorAlejandra Valentino y Claudia Fino
}

El presente trabajo tiene como objetivo investigar el rol de los lectores / espectadores como coproductores de la significación de los contenidos mediáticos a partir del estudio de 2206 comentarios de lectores a una nota publicada por el diario La Nación en la edición digital del 6 de julio de 2010, en la que se tematiza la presencia de inmigrantes latinoamericanos en las villas de la Ciudad Autónoma de Buenos Aires (CABA).

La propuesta aborda la problemática en el siguiente orden de desarrollo:

n La interfase discurso de la información / comentarios.

El estatuto genérico de los comentarios de prensa digital a partir de diferentes rasgos prototípicos.

— La construcción del corpus mediado por ordenador.

- El análisis del corpus.

\section{La interfase discurso de la información/comentarios}

El presente estudio surge como continuación y como profundización de un proyecto de investigación ${ }^{1}$ en el que se indagó cómo, por qué y para qué el discurso de la información refiere, comenta, provoca distintos acontecimientos mediáticos en determinado estado del discurso social. En esa oportunidad, se estudiaron diversos temas / problemas vinculados a la reflexión y al análisis de la interfase entre discurso e información, y se construyeron y se reconstruyeron diferentes objetos discursivos vinculados a problemáticas sociales que tuvieron un alto impacto en el discurso mediático contemporáneo, en general, y en el discurso de la información, en particular. 
A partir de un recorrido teórico muy heterogéneo, que vincula conceptualizaciones sobre el discurso social y/o discurso hegemónico, el discurso de la información y los mecanismos pragmáticos / enunciativos que emergen en los discursos estudiados, se problematizó una propuesta de diseño teórico metodológica para pensar, analizar, extrañar, desnaturalizar un tipo de discurso particular que circula en nuestro medio como es el discurso de la información en la inscripción del discurso social.

Desde esta perspectiva, se analizaron y se estudiaron objetos discursivos relacionados con diferentes problemáticas sociales: vinculadas a la perspectiva de género (aborto, transexualidad, infertilidad), a la visibilidad / invisibilidad de los pueblos originarios, a la educación, los traspasos presidenciales, la ocupación / desocupación, la seguridad / inseguridad, que dan cuenta de cómo determinados problemas sociales que subyacen en el espacio público son semantizados en el discurso de la información (DI). A partir de estas investigaciones, se establecieron algunas coordenadas propias del discurso de la información (Valentino \& Fino, 2016) que son centrales para las reflexiones sobre los comentarios de las noticias en la prensa digital, ya que permiten elaborar algunas hipótesis acerca del rol de los lectores / comentadores en la producción de las noticias.

El discurso de la información comprende un grupo complejo y heterogéneo de géneros y de tipos discursivos que puede definirse, básicamente, a partir de su situación de mediación, lo que algunos autores denominan máquina mediática. Según Patrick Charaudeau (2003), la máquina mediática está constituida por tres lugares: productor, producto y receptor; perspectivas presentes y evidentes en cada pieza discursiva que son absolutamente solidarias en la construcción de los sentidos que cualquier discurso informativo produce.

Ahora bien, estos momentos de la instancia discursiva no son independientes, sino que actúan en forma solidaria. Los sentidos resultantes del acto de información se construyen en una co-intencionalidad, de allí que no representen únicamente la intención del productor de la información, ni tampoco la del receptor, sino que se den en forma solidaria y co-construyan lo que de manera operativa podemos denominar la información. Es a partir de estas reflexiones teóricas que los comentarios de lectores ocupan un lugar estratégico en la categorización del discurso, porque tradicionalmente constituyen la voz de los lectores en la comunicación asimétrica que propone el discurso mediático pero, a su vez, co-construyen los sentidos que circulan alrededor de cada uno de los temas que aparecen en el discurso de la información. 
Si partimos de considerar que todo productor procurará que su interlocutor lo comprenda y modifique el estado de sus conocimientos o actúe de determinada manera, es decir, construya sentidos afines a los propuestos, informar es siempre elegir diferentes estrategias discursivas (que podrán o no resultar efectivas).

El discurso de la información es un discurso de fácil accesibilidad. Nuestras sociedades contemporáneas están interpeladas en forma permanente por este tipo de discurso; somos seres mediados e informados. En este punto, es importante una aclaración: se entiende por DI un grupo complejo y heterogéneo de géneros, tipos, tramas y formatos discursivos que se pueden caracterizar, por ejemplo, a partir de su situación de mediación (diario, televisión, radio, Internet) y que tienen un lugar estratégico en la producción, reproducción, cristalización de sentidos que circulan y que se resignifican en nuestra sociedad. Precisamente, el enfoque del análisis del discurso resitúa el lugar desde donde pensar diferentes formaciones ideológicas y destierra una manera de considerar la «información» como «espejo de la realidad», como «verdad de los hechos», como «fuente objetiva del saber»y, por lo tanto, como sagrada, impoluta, aséptica, objetiva, neutra, lugares desde donde se la ha considerado tradicionalmente.

El cambio epistemológico que implica pensar la información como discurso tiene algunas derivaciones que a continuación se detallan y que serán esenciales para entender el lugar de los comentarios de la prensa digital en la construcción del sentido mediático.

a. La información es pura enunciación, lo que implica que, necesariamente, debemos entender la compleja relación entre discurso y situación de enunciación para aproximarnos a los sentidos que de esa relación se construyen. La información es siempre una elección que se concreta en discursos, una elección no solo de contenidos sino de efectos de sentido para influir sobre el otro.

b. La información se materializa, se visibiliza, se transforma en una multiplicidad de discursos que pertenecen a diferentes lenguajes. Ejemplos clásicos del tema son los DI que circulan en la gráfica, en Internet, en los medios audiovisuales, radiales. Uno de los lugares por antonomasia donde se cristaliza el discurso de la información es la prensa digital.

c. El DI se construye en un doble proceso. Es hacer-saber, lo que implica poner en la escena del discurso determinados conocimientos sobre la actualidad social otorgándoles un valor desde determinadas construcciones colectivas. Según Charaudeau (2003) el sentido se construye en un doble proceso de semiotización: por un lado, el proceso de transformación que implica nombrar un hecho, un evento o un acontecimiento desde una multiplicidad de 
lenguajes y, por otro, un proceso de transacción que otorga significación psicosocial al acto de lenguaje apoyándose en ciertos principios. El DI es una reconstrucción, una especie de «espejo deformante de lo social» (Charaudeau, 2003, p. 15).

d. La información conjuga dos tipos de saberes: los de conocimiento y los de creencia. Los primeros son los que se supone que dan cuenta de las cosas de la manera más objetiva posible, basados en la experiencia, en la observación o en datos científicos y técnicos, aunque es sabido que están atravesados por la experiencia cultural, social, civilizadora. Los saberes de creencia dependen de sistemas de interpretación de lo posible y lo probable, a través de afirmaciones con valor de evidencia desde lo ético, lo estético, lo hedonista y lo pragmático, de acuerdo con juicios estereotipados que circulan en la sociedad (modelo de conformidad social).

e. En el DI se puede distinguir entre valor de verdad y efecto de verdad. Mientras el primero es un valor objetivante y objetivado, producto de una construcción explicativa que se apoya en instrumentos científicos, el segundo se origina en la creencia, en la subjetividad de los sujetos en su relación con el mundo, con un saber de opinión. El efecto de verdad está modulado por los motivos para dar una información, por la identidad social de quien brinda la información y por la pruebas que tiene el informador para otorgar veracidad.

f. Informar es siempre elegir diferentes estrategias discursivas, es decir, construcciones del discurso con ciertas intencionalidades donde la «objetividad», la «neutralidad» son efectos de sentido a partir de las estrategias discursivas que selecciona el macro enunciador para hablar sobre un tema social.

g. El discurso de la información, al igual que todo discurso, no es transparente, esto es debido a que los discursos son creados, formados y posicionados a través de un proceso de construcción cada vez más complejo.

h. Para poder reconstruir el sentido / los sentidos del discurso de la información debemos tener en cuenta por lo menos tres dimensiones analíticas: el campo de conocimiento que trata, la situación de enunciación en la que se inserta y el dispositivo en el que circula. La situación comunicativa es algo así como un escenario teatral, con sus limitaciones de espacio, tiempo, relaciones, palabras, en el cual se interpretan los intercambios sociales y se les otorga un valor simbólico. Esta idea de escenario teatral es muy productiva para estudiar los comentarios de las noticias de prensa. 


\section{i. Las transformaciones culturales y los nuevos modos de acceso a la información han} reconfigurado las formas constitutivas del DI, lo que implica un cambio radical en el concepto de información, de actualidad en la información y de veracidad en la información. El formato discursivo se ha modificado sustancialmente a partir de la irrupción de las nuevas tecnologías de la comunicación como de las redes sociales, tanto en la producción como en la recepción de la información.

A partir de estas investigaciones, y dada la relevancia que ha tenido a lo largo de los diferentes casos investigados un tipo de formación discursiva particular, el propósito de este trabajo es estudiar los comentarios de lectores a las noticias de la prensa digital porque son lugares estratégicos para seguir profundizando el estatuto discursivo de la información, así como la co-construcción de sentidos que produce el discurso mediático / informativo.

\section{E estatuto genéric o de los comentarios de prensa digital a partir de diferentes rasgos prototípic os}

Los comentarios de lectores son espacios discursivos que habilitan los medios electrónicos para que, «supuestamente», los lectores expresen sus opiniones y/o pareceres sobre un tema en particular. En este sentido, el medio analizado aporta rasgos genéricos más que interesantes para pensar estos espacios discursivos. El mismo medio sostiene que la apertura del espacio de los comentarios supone

\footnotetext{
[...] un proceso de mayor intercambio y apertura entre el medio de comunicación y sus lectores, cada vez más habituados a generar su propio contenido, enriquecer el existente con sus puntos de vista e intercambiar sus opiniones en diferentes espacios digitales (La Nación, 15/7/2007, en línea).
}

Existen escasas investigaciones que den cuenta del carácter genérico de los comentarios. En líneas generales, se entienden de dos maneras diferentes: a) como un género compuesto, el artículo de noticias participativo, formado por un género prototípico y más estable, vinculado a la actividad periodística (noticia, reportaje, columna de opinión), y un género periodístico emergente, como el comentario electrónico; b) como un espacio cedido por los medios para que los usuarios puedan interactuar (Moya Muñoz, 2015). 
En este sentido, existen estudios que plantean que los comentarios de la prensa digital son una especie de conversación o de diálogo entre los diferentes participantes del intercambio, que mantienen rasgos prototípicos de la oralidad - como el turno, la alternancia, la correspondencia- pero que se realizan mediante un código gráfico en el que los hablantes intercambian roles en forma permanente.

Ahora bien, en el caso estudiado, los comentarios constituyen un lugar discursivo estratégico para investigar las características propias del discurso de la información, ya que son un espacio fundamental para dar cuenta tanto de la continuidad argumental como disruptiva de la línea narrativa / editorial que se desarrolla en las notas publicadas en los portales investigados. Los comentarios agregan, condensan, ridiculizan, parodian, ponderan, semiotizan cada uno de los temas sociales como una continuidad discursiva de la trama que se inscribe en el artículo donde aparecen. En todos los casos, se trata de discursos ligados, subalternos, subsidiarios de las notas de los portales digitales donde emergen.

Bajo la forma de opinión de los lectores, espacio de intervención, plantean posiciones absolutamente radicales frente a cada uno de los temas en un mosaico discursivo que polemiza y/o profundiza la posición del medio frente a la coyuntura que se discute. Los comentarios son formas discursivas que exceden el hecho de la simple opinión de los lectores y la supuesta dialogicidad que tantas veces fue elogiada cuando se intentó describir y explicar el discurso de internet 2.0 como un lugar de simple evolución de la web, donde los usuarios son extremadamente activos, producen, generan y resignifican contenidos. La idea de la democratización de los espacios de discurso digital merodeó, fundamentalmente, en el inicio de estas formas de comunicación masivas.

A medida que se avanza en el análisis del corpus estudiado, se observa cómo en los comentarios confluye una multiplicidad de voces sociales a través de diferentes mecanismos enunciativos (refranes, dichos, enunciados referidos, ironías, parodias, frases hechas) que cristalizan sentidos que se desarrollan en las notas en cuestión aunque se quiebra de manera evidente el registro tradicional propio de los discursos informativos. Como señalan María Cristina Arancibia y Lésmer Montecinos (2013), en los comentarios prevalece la utilización de un lenguaje procaz, coloquial, corriente, descuidado, y, fundamentalmente, es donde aparecen inscripciones de diferentes formas de violencia, especie de guerras verbales que no solo se producen en los blogs, chats, foros, twitter sino, precisamente, en estos lugares que tradicionalmente estaban reservados para otro tipo de interacciones verbales. A diferencia de otros espacios tradicionales donde aparecía la voz de los lectores, como las cartas de lectores, la forma discursiva que adoptan los comentarios merece un tratamiento y una investigación minuciosa. 
En los comentarios de la prensa digital se plasma de manera evidente la hibridación, la multimedialidad y la inestabilidad del discurso digital. Numerosos autores señalan el continuum que implican estas manifestaciones verbales, que si bien son escritas están altamente determinadas por lo coloquial, lo polémico controversial y la disputa en términos discursivos que se inscriben en los diferentes intercambios lingüísticos. Precisamente, constituyen un espacio discursivo que posee un valor estratégico para estudiar la inestabilidad y/o la hibridación de los discursos digitales ya que borran, mezclan, subalternan las tradicionales barreras para delimitar el principio y el fin de la línea argumental del texto que los antecede.

A lo largo del análisis nos hemos preguntado, una y otra vez, en qué medida los comentarios no operan como una continuidad de lo dicho en el cuerpo central del diario, como así también en qué medida estos comentarios habilitan no solo lo no dicho (en términos pragmáticos) sino que, de alguna manera, posibilitan lo indecible en términos sociales. En forma recurrente, los comentarios construyen un lugar privilegiado donde se (re)producen diferentes tipos de violencias mediante la publicación y la difusión de temas, palabras estigmatizantes, argumentos, estereotipos, dichos, valoraciones, patrones socioculturales, relatos, así como también a partir de múltiples estrategias de semiotización cada vez más complejas que van desde la agresividad leve y moderada a la violencia cada vez más explícita y brutal.

En el terreno de lo verbal, podríamos establecer la diferencia entre lo que son actos disuasorios o actos de inhibición, del tipo de la amenaza, que encarnarían la agresividad: se trata de intimidar bien para defenderse de algo (contraagresividad) o para mantener una postura fuerte frente al grupo. [...] La violencia, en cambio, da lugar a la ejecución de un acto ilocutivo que va a dañar socialmente al interlocutor: por ejemplo, el insulto, la ridiculización, el empequeñecimiento, la usurpación de la palabra, es decir, todos aquellos actos que atentan contra la dignidad de la persona. Por lo tanto, hay actos ilocutivos agresivos y actos violentos [...]. La agresión puede plantearse de manera simple, haciendo referencia concreta a personas, lugares o situaciones de manera directa; o elaborada, a través de figuras retóricas como metáforas, ironías, sarcasmos, usos poéticos, analogías, para de manera ambigua o vaga para agredir a otro usuario (Rodríguez \& Alcaide, 2008, citado en Noblía, 2015, p. 22). 
Por lo tanto, resulta interesante e importante pensar el estatuto genérico a partir de estas consideraciones del discurso de la información como así también de diferentes estudios vinculados a la comunicación y/o al periodismo, tal como sostiene Patricio Moya Muñoz (2015).

\section{Consideraciones acerca de la materialidad del corpus}

El presente trabajo se realizó a partir de la nota «Hay mayoría de extranjeros en las villas. Más de 140.000 ciudadanos de países vecinos reciben planes sociales en la Capital; cayó la migración desde el interior del país», escrita por Daniel Gallo en la edición digital del diario La Nación del 6 de septiembre de 2010 y en la que se registran, desde la fecha de publicación hasta el 29 de diciembre de 2015, un total de 2206 comentarios.

Tal como sostienen Ana Mancera Rueda y Ana Pano Alamán (2014), a simple vista, la construcción del corpus con interacciones que se originan en internet parece sencilla por la facilidad, la accesibilidad y la digitalización del material; sin embargo, a medida que se avanza en el análisis emerge la complejidad de estas piezas discursivas en tanto formas híbridas entre lo escrito y lo oral, con una impronta muy fuerte de las marcas gráficas y de las limitaciones tecnológicas, pero también con una continuidad argumental polémica con la línea editorial de los medios en los que aparecen. La extensión de los comentarios, tanto desde lo cuantitativo (15000 palabras vs 650 palabras) como desde la temporalidad (los comentarios aparecen desde el 6/9/2010 hasta el 29/11/2015), excede cualquiera de las notas digitales de los periódicos.

Para el análisis que se presenta a continuación, se siguió el prototipo ampliamente utilizado por la investigación en la temática de los corpus digitales que analiza los factores del medio y los factores situacionales, y que pueden resumirse en el siguiente gráfico: 


\begin{tabular}{|c|c|}
\hline CARACTERÍSTICAS & DEFINICIÓN \\
\hline Sincronicidad & $\begin{array}{l}\text { Conexión al mismo tiempo } \\
\text { entre los usuarios }\end{array}$ \\
\hline Transmisión del mensaje & $\begin{array}{l}\text { La transmisión se realiza } \\
\text { mensaje por mensaje o signo } \\
\text { por signo }\end{array}$ \\
\hline Persistencia & $\begin{array}{l}\text { El tiempo que se mantienen } \\
\text { los mensajes almacenados }\end{array}$ \\
\hline Tamaño del mensaje & $\begin{array}{l}\text { Número de caracteres que } \\
\text { el sistema permite incluiren } \\
\text { un único mensaje }\end{array}$ \\
\hline Canales de comunic ación & $\begin{array}{l}\text { Texto, a udio, vídeo, } \\
\text { imágenes, etc. }\end{array}$ \\
\hline Mensajes a nónimos & Autoría desconocida \\
\hline Mensajes priva dos & $\begin{array}{l}\text { Un usuario puede contactar } \\
\text { en privado con otro }\end{array}$ \\
\hline Filtración & $\begin{array}{l}\text { Hay a dministra dores que } \\
\text { filtran los mensajes }\end{array}$ \\
\hline Cita & $\begin{array}{l}\text { Los mensajes se pueden } \\
\text { incrustar en otros mensajes } \\
\text { para facilitarla interacción }\end{array}$ \\
\hline Formato de los mensajes & $\begin{array}{l}\text { Detemina la presentación } \\
\text { visual de los mensajes }\end{array}$ \\
\hline Estructura de la partic ipación & Número de participantes \\
\hline $\begin{array}{l}\text { Característic as de los } \\
\text { partic ipantes }\end{array}$ & $\begin{array}{l}\text { Característic as ideológic as, } \\
\text { demográfic as, cultura les, } \\
\text { etc. }\end{array}$ \\
\hline Propósito & Metas de la interacción \\
\hline Tópico & Tema \\
\hline Tono & Formal o informal \\
\hline Actividad & Acción llevada a cabo \\
\hline Normas & $\begin{array}{l}\text { Prá c ticas esta blecidas } \\
\text { acepta das por el grupo }\end{array}$ \\
\hline $\begin{array}{l}\text { Código (lengua y/o } \\
\text { variedades de lengua) }\end{array}$ & Variedades del español \\
\hline
\end{tabular}

Gráfico 1 | Prototipo de investigación temática corpus digitales (Fuente: Moya Muñoz, 2015) 
En el caso de nuestro análisis, consideramos necesario incluir, también, una serie de factores enunciativos y/o pragmáticos que serán cruciales. Por esto, proponemos un prototipo provisorio con el que se ha trabajado en el análisis del discurso de la información y que se adapta, especialmente, para abordar el análisis discursivo de los comentarios de la prensa.

A continuación, señalamos una serie de categorías incluidas en los protocolos de análisis del DI.

Mecanismos inferenciales

Uso de diferentes recursos retóric os: ironía, metáfora, personificaciones, preguntas retóricas, parodia, metonimia

Temporalidad extendida

Utiliza ción de marcas gráficas con a lto valor pragmático

Mecanismos polifónic os:

extua les/ enuncia tivos

Modaliza ción / Valoración

Actancialidad. Participantes / evento

Polemicidad disc ursiva
Reconstrucción de lo dicho a partir de lo no dic ho: implic aturas, ac tos de habla, sobreentendidos.

Mecanismos para persuadir, evaluar, denostar, deslegitimar, argumentar.

Resignific ación de la temática con el paso del tiempo.

Uso de mayúsc ulas, puntos suspensivos, signos de admiración y exc la mación de manera diferente al uso del discurso escrito. Evidencia la hibridación.

Enunciados referidos directose ind irectos, refranes, dichos populares, frases hechas. Marcas de desdoblamiento del sujeto, uso de la adversativa, diferentes tipos de negaciones.

Utilización de diferentes mecanismos de modalización.

Polaridad en la descripción de los partic ipantes del evento. Valoración (+/ -).

Disc usión con otro que piensa/expone una postura radic almente opuesta.

Gráfico 2 Serie de categorías incluidas en los protocolos de análisis del DI (Fuente: elaboración propia) 


\section{E análisis del comus}

\section{Inferencias e implícitos}

En primer lugar, es importante iniciar el abordaje del corpus de comentarios de lectores desde una perspectiva pragmática, porque nos permite dilucidar diferentes aspectos.

Paul Grice (1991) introduce el concepto de implicatura, un tipo especial de inferencia pragmática que se basa en la distinción entre lo que se dice y lo que no se dice pero que se implica al decir lo que se dice. Para Grice, hay máximas o reglas que responden a un principio cooperativo de conversación: de cantidad (referida a la información que debe darse como necesaria), de cualidad (referida a la veracidad de lo dicho y con pruebas que lo sustenten), de relación (referida a lo pertinente de lo que se dice) y de manera (referida a la claridad, la brevedad y el orden del decir). Cuando se viola alguna de estas máximas se genera una implicatura.

Grice distingue dos tipos de implicaturas: convencionales y conversacionales, aunque la diferencia no siempre es nítida. La implicatura convencional está vinculada a las palabras, aunque depende de algo adicional a su significado, en tanto que la implicatura conversacional se relaciona con pautas que regulan la conversación. Las implicaturas conversacionales son fenómenos pragmáticos en los que no hay vinculación con las palabras o las frases, sino que derivan de factores del contexto y de las convenciones. Grice distingue entre implicaturas conversacionales generalizadas, que no dependen del contexto en el que se emiten, e implicaturas conversacionales particularizadas, que dependen del contexto de emisión.

Extraemos algunos pasajes de los comentarios ${ }^{2}$ en los cuales encontramos una serie de implicaturas, la mayoría de las cuales quiebran las máximas de modo intencional para ser captadas como implicaturas, por lo cual esta violación abierta constituye una estrategia que potencia el sentido (Reyes, 1990). No nos detendremos en un análisis minucioso de las máximas violadas en cada caso para focalizarnos en los implícitos y en los presupuestos que dan cuenta de una serie de representaciones y de argumentos de los lectores que evidencian discriminación, desde una tópica que sostiene el encadenamiento de los enunciados y que forma un muestrario de lo probable propio de una doxa de un discurso exotérico, de opinión pública (Angenot, 2010), uno de cuyos exponentes destacables es el discurso de los medios que pugna por cristalizarse y por hacerse vigente en la construcción del sentido común. Recordemos que Marc Angenot (2010, p. 38 y ss.) caracteriza la tópica como «el conjunto de los lugares (topoi) o presupuestos irreductibles 
del verosímil social», presupuestos colectivos que producen lo opinable y que resultan necesarios como configuración del «orden de la veridicción consensual», inevitable en cualquier discursividad.

\section{tienen mas derechos ellos que nosotros que nacimos en la argentina}

En este ejemplo, dentro del tópico que evalúa en términos de más / menos, el hablante da como hecho natural y lógico que los derechos de los habitantes tienen jerarquías establecidas de acuerdo con el lugar de nacimiento. Por eso, se expresa como algo paradójico que «ellos», los inmigrantes, tengan más derechos que los argentinos («nosotros»). Ser argentino necesariamente debe ser una ventaja o un privilegio en términos de derechos de los ciudadanos. Detrás de esta suposición existen configuraciones implícitas acerca de lo que se considera «más» que encadena lugares comunes que responden a una tópica sobre representaciones, por ejemplo, acerca del trabajo, la propiedad privada, el derecho por nacimiento, el Estado, las políticas sociales, los programas de asistencia social, la pobreza, las villas, la delincuencia, los derechos humanos, por nombrar algunos tópicos implícitos en la oposición más derechos / menos derechos.

- Poner control no es ser xenofobos!! Todos los paises serios, lo hacen!!

En este caso, encontramos al menos tres supuestos importantes que sustentan argumentativamente lo que se afirma: en principio, el hablante polemiza desde el enunciado negativo con la afirmación de que oponerse a los beneficios y a los derechos de los inmigrantes sea ser xenófobo, es decir que supone una argumentación contraria a la suya que podría caracterizarlo como tal; luego, propone «poner control», con lo cual da como un hecho que no hay control o que hay descontrol desde el Estado acerca de la inmigración; por último, utiliza una figura retórica, la sinécdoque hiperbólica (la parte por el todo) que responde a una subjetividad ideológica difusa, que evalúa en términos de serio / no serio a los países, cuya diferencia consiste - al menos en un aspecto- en poner control a la inmigración; es decir, da por sentado que los demás lectores comparten ese modo de evaluar la seriedad de un país y que la seriedad de un país es algo que se debe imitar. 
- Anda a bolivia, Brasil o chile a usurpar casas y terrenos y utilizar gratis la salud y educacion, a ver que te dicen!

Tres implícitos nos resultan relevantes en este comentario. Por un lado, se supone la certeza de que en nuestro país los inmigrantes usurpan casas y terrenos; por otro, que salud y educación gratuitas es algo extraordinario si se es extranjero; finalmente, y como argumento de la expresión figurada (en un acto de habla indirecto cuya intención es la de aseverar que en Bolivia, Chile y Brasil no permiten que ningún inmigrante ocupe terrenos y tenga acceso a la salud y a la educación de forma gratuita), presenta los tres países latinoamericanos que se mencionan al final de la nota para dar la cifra de los extranjeros que recibieron la radicación definitiva entre 2006 y 2010, constituyendo una sinécdoque (la parte por el todo) que el comentarista supone con otras posibilidades para la inmigración, a través de un tópica fundada en la razón de lo bueno y de lo malo existente en los lugares de origen de los beneficiados. Si en sus países de origen no nos permiten a nosotros esos hechos, permitírselos a ellos en la Argentina es absurdo o al menos incomprensible. Naturalmente, hay una implicación más en el hecho de considerar que restringir los derechos de los inmigrantes y diferenciarlos en posibilidades de nuestros derechos es algo obvio del deber hacer del Estado.

- Para los progres: Cambiemos el término extranjero por «no invitado», que en definitiva es lo que los define. Ahora en vez de hablar de Argentina, hablemos de la casa de cualquiera, progre o no progre. Recibirían a cualquiera en su casa? De cualquier religión, ideología, manera de vestir y hábitos de higiene? De hecho lo hacen? Se llevan a algún villero a dormir en su living? Hasta los famliares son bienvenidos en casa por un período de tiempo limitado y deben someterse a las reglas estipualadas. No pueden abrir la heladera y vaciarla, pretender dormir indefinidamente ni ser mantenidos.

En este enunciado, a través de la forma de nombrar a un grupo opuesto a su posición, el hablante define de modo estereotipado, que incluye una burla (no define al progresista o a quien es de izquierda sino a quienes tienen la pose de serlo, sobre todo discursivamente), a quienes supone que defienden los derechos de los inmigrantes; es decir que hay una concepción de prejuicio ideológico que se basa en la idea de un colectivo estándar progre que se reúne en pos de la defensa del inmigrante. Establece, luego, una especie de alegoría que —como toda figura retórica- intencionalmente provoca una implicatura. En ella, el paralelismo instaurado (país-casa, extranjero-no invitado, derechos y deberes del ciudadano en 
el país-reglas estipuladas de la casa, etc.) se da como una equivalencia perfecta que supone obvios (lugar común de los presupuestos y los implícitos de una clase social, de una doxa pequeño burguesa consensuada) los comportamientos y las premisas de la propiedad privada de los hogares argentinos. Además de presuponer que nadie puede llevar a dormir a su casa a «un villero», lo que incluye el sobrentendido de que todos los villeros son iguales y de que todos los villeros son personas no gratas.

\section{- Por qué debemos "ayudarlos" a ellos en vez de pensar en el futuro nuestro y de nuestros hijos? Por qué tengo que mantenerlos con impuestos?}

Otra vez se recurre a la figura retórica para generar una implicatura. En este caso, se emplean preguntas retóricas cuya fuerza ilocutiva está focalizada en aseverar, enfáticamente, el sinsentido de lo que se formula como interrogación. En la primera pregunta se presupone, a través de un topos que dicotómicamente establece oposiciones irreconciliables, que beneficiar a los inmigrantes redunda necesariamente en el abandono de la preocupación por el futuro propio y de la propia progenie. La presunción, por tanto, consiste en dar por sentado que favorecer a los ciudadanos extranjeros es desfavorecer a los argentinos.

En la segunda pregunta se presupone que cualquier plan de ayuda estatal propicia la falta de necesidad de trabajar, desde una doxa propia del lugar común que solo el esfuerzo y el trabajo merecen apoyo y que la ayuda solo fomenta la haraganería y mantiene la indigencia, difundido extensamente por el discurso de la información monopólico que se opone a las políticas públicas orientadas a una inclusión social. ${ }^{3}$

Además, también se presenta en la pregunta una implicatura convencional configurada por la creencia de que los impuestos de los ciudadanos argentinos son los que pagan la implementación de estos planes sociales. En ella se da por certera la creencia de ser víctima del injusto uso que realiza el Estado de los recursos impositivos recaudados. Esta implicatura responde a la misma serie de presupuestos colectivos de la idea de merecimiento en relación con el trabajo y el esfuerzo, sustentada, también, en el lugar de nacimiento, la vivienda propia - adquirida o alquilada con el fruto del trabajo-, los derechos de los ciudadanos que cumplen con los deberes obligatorios mediante la paga de impuestos, la equiparación de la trayectoria propia de habitante del suelo argentino con la de los otros (extranjeros, pobres, desempleados, villeros), junto con el rechazo de toda opción que no sea idéntica a lo autorreferencial. 
- ... a lo mejor no todos son delincuentes, pero cuando la policia persigue a alguien y se mete en la villa recibe piedras, puteadas y esconden al delincuente, cosa que para mi los convierte, por lo menos, en complices. Y no me vengas con ese discursito barato de que no todos son delincuentes porque la "fama" de las villas no es gratuita, o me vas a decir que no es el nido de criminales?

La implicatura, en este caso, se presenta a partir de la posibilidad de dudar acerca de lo que el mismo comentarista sostiene, esto es, que todos los habitantes de una villa son delincuentes. Por lo tanto, lo que se presupone en ese reparo es que se admite la falta de pruebas para una aseveración que puede ser hiperbólica, y «no todos» da lugar a un reconocimiento de esa exageración dada por el cuantificador universal «todos».

La duda expresada resulta la estrategia discursiva que permite potenciar una serie de nuevas implicaturas, porque es cancelada de inmediato con el marcador discursivo «pero» (polifónico y argumentativo) y revela que la concesión del beneficio de la duda fue una estratagema argumentativa para subrayar los implícitos que sostiene el hablante acerca de las villas y los villeros, porque finalmente descalifica como «discursito barato» la proposición predicativa «no todos son delincuentes», admitida antes como probable.

Esta serie de presuposiciones pragmáticas establecen, en primer lugar, que «alguien» perseguido por la policía es delincuente; además, que los habitantes de la villa apedrean e insultan a la policía que busca a un delincuente; también que los delincuentes que se esconden en una villa encuentran protección en ella; y, finalmente, en un crescendo argumentativo, la conclusión que resulta de una pregunta retórica cuya función pragmática es provocar una implicatura, porque su fuerza ilocucionaria es la de aseverar enfáticamente que la villa es nido de criminales porque se presupone que su «fama» fundamenta esa verdad.

Esta cadena de presupuestos responde a una tópica que configura una doxa que estigmatiza, discrimina y criminaliza la pobreza, sostenida por implícitos acerca de la villa, los habitantes de la villa, la delincuencia, la pobreza, la seguridad, la policía, los discursos de inclusión, los discursos mediáticos, los discursos de opinión común, la fama. 
Otra propuesta importante y fundamental para nuestro análisis es abordar — desde una perspectiva que considera el discurso de la información como construcción incluida en procesos que evidencian lo discursivo como acción social- el análisis de la construcción lingüística de diferentes temáticas y problemáticas sociales, que indudablemente expresa ideología, delimita identidades y confecciona sentidos, mediante la convención que se establece no solo por el sistema lingüístico mismo sino también por un sistema de valores que se actualiza en lo discursivo.

La selección de las palabras y su disposición en las frases permiten vincular intenciones y valoraciones acerca del mundo del locutor. Todo lenguaje es ideológico, todo en las piezas de la lengua señala maneras de conocer y de representar el mundo que no son necesarias ni universales, que entrañan posturas generales y pactos sociales, y que ocupan una posición en la economía de los discursos sociales.

En el marco de la teoría de la enunciación, Émile Benveniste ([1977] 2008) sostiene que «la enunciación supone la conversión individual de la lengua en discurso» (p. 83), es decir que discurso, en su extensión más amplia, es «toda enunciación que supone un hablante y un oyente, y en el primero, la intención de influir de alguna manera en el otro» (p. 84). El hablante se apropia del aparato formal de la enunciación de modo egocéntrico (ego/hic/nunc), se instaura como locutor e instaura al receptor como alocutario, utilizando parte de este sistema; y lo hace mediante un conjunto de signos específicos, los deícticos, y un conjunto de procedimientos sintácticos, morfológicos y semánticos que fueron agrupados posteriormente como modalidades y subjetivemas. Entonces, estas marcas del sujeto productor de enunciados remiten, en primer lugar, al locutor, a su tiempo y espacio, y, en segundo lugar, al alocutario, cuyo tiempo y espacio son, por lo general, los mismos que los del locutor.

En la medida en que el sujeto es el origen de su discurso, y que este es una representación de lo real, un recorte probable con la marca de su formación social e ideológica, podemos decir que la utilización del lenguaje es siempre subjetiva y que, a su vez, la objetividad resulta un efecto de sentido más: un discurso objetivo es solamente el que busca ocultar a su locutor mediante una utilización particular de los elementos del aparato formal de la enunciación.

En este sentido, de qué modo se nombran los acontecimientos, los objetos, los participantes de una situación, responde a evaluaciones desde competencias ideológicas y culturales que se ponen en juego en la comunicación. 
Abordamos dos categorías relevantes en nuestro análisis - que ejemplificamos con enunciados extraídos de los comentarios- para indagar lo enunciativo, que ofrece un complemento importante de la perspectiva pragmática ya ejemplificada: en principio, la inscripción del hablante en el discurso, como delimitación de lo identitario, la pertenencia a un grupo, la configuración de su lugar de discurso; y en esa línea, los elementos léxicos con carga valorativa, como modo de conceptualizar personas, acciones, procesos, etcétera.

Uno de los componentes propuestos por Angenot (2010, p. 42 y ss.) para investigar la hegemonía discursiva es el que denomina como egocentrismo-etnocentrismo. Es decir, un enunciador legítimo central que se atribuye el derecho a hablar de la alteridad, cuya (des)calificación se vincula siempre con él mismo, incluido en un «nosotros».

La isotopía que introduce el enunciador configura su identidad y la de quienes se incluyen en ese «nosotros», al mismo tiempo que caracteriza la alteridad:

—no es inmigrante/extranjero

No estoy en contra de los inmigrantes, es más, en todos los paises los hay. Como en muchos otros países, los inmigrantes realizan el trabajo que los naturales no realizan. Pero tampoco es joda

No se como hacer para decir que me parece una injusticia que en los hospitales públicos a veces no haya lugar para atender a un argentino porque están sobrepasados con extranjeros de países limítrofes que han venido a hacerse atender aquí gratis y no parecer un xenófobo.

— es ciudadano argentino de nacimiento estamos hartos que nos tomen de tontos, le dan subsidios a inmigrantes, tienen mas derechos ellos que nosotros que nacimos en la argentina.

घe diferencia y distancia de la figura del pobre / desocupado / villero Porque siempre junto a un pobre hay suciedad o cosas tiradas a su alrededor? aunque no tengan donde depositar los residuos deberian tener un poco de amor propio y entre todos pasar la escoba y juntar aquello que es insalubre para sus congeneres. Esto se hereda?

Me pregunto cuántos de esos animalillos del señor son Argentinos. Claro que va más allá de la nacionalidad... es siempre el "vale todo" para los villeros. 
nes trabajador

piden dinero de los que APORTAMOS TODOS LOS ARGENTINOS QUE LABURAMOS

E respeta la inmigración europea de principios del siglo XX y rechaza la inmigración latinoamericana

Los que vinieron de Europa a poblar la Argentina era gente de trabajo que hicieron la patria grande, pero de ninguna manera podemos comparar a los indios bolivianos y peruanos que cruzan la frontera y se instalan en las villas, toman inmuebles, reciben planes trabajar, asignaciòn universal, etc.

Mis abuelos inmigrantes de europa siempre decian,"seremos pobres pero limpios, y nuestros hijos y nietos, deberan siempre trabajar o estudiar".

Hablan de la inmigración europea al país, pero no se olviden que la Argentina en ese momento era un país "lleno de oportunidades" y vinieron buscando un futuro mejor L$A-B-U-R-A-N-D-O$.

Como hacer para hacerme entender que esta inmigración no tiene absolutamente nada que ver con la inmigración europea de antaño y no parecer un xenófobo

—apoya las políticas sociales exclusivas y rechaza las inclusivas

La culpa de esta invaciòn de gente extranjera la tiene el gobierno, ya que no hay una politica de inmigraciòn correcta.

Yo estoy a favor del muro que hizo EE UU por ej.Así deberíamos hacer nosotros en la frontera con Bolivia, uno bien alto.Quien cruza la frontera en EE UU, inmediatamente lo suben a la patrulla y lo vuelven a dejar en territorio mexicano.Acá, es un asilo de delincuentes de toda calaña.

En cualquier país NORMAL, al que no aporta, se lo deporta. Que mantengan su vagancia en sus respectivos países o que vayan a hacer autopistas y avenidas al otras provincias con menos población.

ejemplo deberiamos tomar de los paises desarrollados, que no permiten que otras culturas traigan su forma de vivir q no tiene nada q ver con la nuestra. 
—es xenófobo

ES HORA DE QUE SE LOS EXPULSE A TODOS y esos trabajos se los asignen a argentinos que estàn cobrando planes sociales subvencionados con dinero de los aportantes al sistema previsonal

Todos los inmigrantes ilegales o que cometan delitos en Argentina deben ser deportados ENSEGUIDA. No como ahora, que regentean el narcotráfico, toman como rehenes en las villas a compatriotas nuestros, y encima quieren tierras, subsidios como si fueran argentinos. Tiene que haber un derecho para los argentinos y otro especial para extranjeros

creo q es una cuestion cultural de los inmigrantes de nacionalidad boliviana, peruana y paraguaya.... ni se preocupan por hacer los tramites de visa, ni de obtener el dni....

La puesta en escena discursiva de este sujeto plural que se atribuye derechos, que juzga y que clasifica, es, sin dudas, polifónica, porque el «nosotros» es un «yo» con el que se identifica la doxa que rechaza a quienes no cumplen los requisitos de ese yo (la alteridad del inmigrante, sin trabajo ni casa) y valida la discriminación, porque el dispositivo hegemónico es favorable a la clase dominante, cuyo modo de vida es deseable y fácil de sentirlo como provechoso.

La exclusión es explícita en la selección léxica para nombrar la alteridad: inmigrantes, ellos, gentuza, extranjero, no invitado, villeros, mantenidos, delincuentes, cómplices, criminales, pobres, vecinos, esta invasión de gente extranjera, indios bolivianos y peruanos, habitantes paraguayos, estos inmigrantes, vagancia, los morochos, animalillos del señor, inmigrantes ilegales, extranjeros de países limítrofes, pasados de alcohol, borrachos en las calles, un desastre.

La carga valorativa negativa también se extiende a las formas que se seleccionan para nombrar acciones y procesos en los cuales el individuo inmigrantes está involucrado: no laburan, viven de los demás, destruyen el país, usurpan, se aprovechan de todo y de todos, hay suciedad o cosas tiradas a su alrededor, se apropian de terrenos ajenos, se instalaron, se instalan en las villas, toman inmuebles, reciben planes trabajar, asignación universal, etc., no aportan nada, vaguean, escuchan cumbia todo el día antes de agarrar un pico y una pala, reclaman planes, piden dinero de los que aportamos, se educan gratis, se hospitalizan gratis, cometen delitos, se están reproduciendo como ratas, tienen seis hijos de promedio, regentean el narcotráfico, toman como rehenes en las villas a compatriotas nuestros, y encima quieren tierras, subsidios. 
El orden simbólico de estas frases impone una forma de evaluar prácticas y creencias en las que, además de la perturbadora discriminación y el posicionamiento en una superioridad etnocéntrica argentina (porteña o bonaerense, casi siempre), desconoce lo esencial respecto de esta cuestión del sistema democrático, desarrollado en el preámbulo de nuestra Constitución, que procura «asegurar los beneficios de la libertad para nosotros, para nuestra posteridad y para todos los hombres del mundo que quieran habitar en el suelo argentino».

Los enunciados, repetimos con Mijaíl Bajtín ([1985] 1976, p. 245 y ss.), son eslabones que constituyen cadenas dialógicas, se reflejan entre sí, evocan y hacen eco de otros enunciados atravesados por conceptualizaciones y por objetivaciones del mundo. Es decir que el acceso a una dimensión ideológica de lo que se representa en el discurso no se exhibe solo en lo que refieren las palabras sino también en las evocaciones, en esos ecos que configuran ideologemas compartidos por una doxa que sostiene los intereses de un grupo.

Además de constituirse una red semántica peyorativa como estrategia básica del discurso ideológico, que necesita de la detracción del otro y de ligarse al discurso más agresivo, desde una dimensión performativa establece una violencia mayor, porque esa polarización extrema retoma la visión del otro deshumanizado tan frecuente en la historia y en la literatura argentinas para identificar a la alteridad que estorba y que debe ser exterminada. Podemos ampliar la relación con la dicotomía sarmientina: de lo civilizado a lo bárbaro, pues si bien los términos se resignificaron en distintos tipos sociales hasta nuestros días - gaucho, indio, inmigrante, obrero, subversivo, para el atributo de bárbaro- la barbarie tuvo que ser deshumanizada para persuadir discursivamente de que en verdad lo era. 4

\section{Conc lusiones}

Socializar este tipo de ejercicios no solo abona el proceso de investigación que realizamos. Fortalece la convicción de los integrantes del equipo de la necesidad de profundizar ciertos debates y reflexiones, en conjunto con la sociedad, en torno a

— el rol de los medios de comunicación y su centralidad en la construcción social del sentido, especialmente en relación con la problemática del estatuto de la información; 
los múltiples mecanismos lingüísticos / discursivos que operan en la discursividad social y que se naturalizan en torno a ciertos temas / problemas de la sociedad argentina actual;

- la injerencia de las redes sociales, la prensa digital y el presupuesto de una activa participación —-democrática, ciudadana- en la construcción de contenidos a través de los comentarios;

la vigilancia epistemológica focalizada en los anclajes teórico-metodológicos vinculados a la disciplina y la necesidad de reconfigurarlos ante la hibridación de ciertos tipos discursivos en un tipo de discurso particular, como lo es el discurso de la información.

Por ello, consideramos que la propuesta avanza en algunas cuestiones centrales que gravitan de forma sustantiva en los tipos de violencias que se activan / construyen en la prensa digital al momento de hablar, de referir, de enunciar sobre el otro. Allí enunciamos cómo se subestima, se violenta, se margina, se menosprecia, la figura del otro.

El consentimiento, la adhesión, la legitimación, la aceptabilidad, la justificación de determinados temas que circulan en la sociedad coexisten con el resentimiento, la resistencia y las acciones hostiles o antagonistas, y se encuentran en un repertorio de representaciones de lo social que pueden ser pensadas como formas ideológicas. Ahora bien, la ideología lejos de ser una única y parcial visión de la realidad es un entramado de «versiones» nunca monolíticas, lugares donde explota el sentido y conforman un complejo ideológico.

La situación comunicativa es algo así como un escenario teatral, con sus limitaciones de espacio, tiempo, relaciones, palabras, en el cual se interpretan los intercambios sociales y se les otorga un valor simbólico. Coadyuvan en la construcción de la espectacularización de las violencias ya que son un lugar privilegiado donde se inscriben las diferentes modalidades de violencias.

En este caso de estudio, pudimos identificar analíticamente la selección léxica para nombrar la alteridad que posiciona tanto una exclusión explícita en torno a los derechos humanos como una implícita a través de las implicaturas analizadas; relevamos la utilización de cargas valorativas negativas que se seleccionan para nombrar acciones y procesos en los cuales el individuo inmigrante está involucrado y, fundamentalmente, la identificación analítica realizada en torno al orden simbólico que estas frases imponen 
al evaluar prácticas y creencias en las que, además de la perturbadora discriminación y el posicionamiento en una superioridad etnocéntrica argentina (porteña o bonaerense, casi siempre), desconoce lo esencial respecto del sistema democrático en los procesos de reconocimiento sobre la inclusión, el acceso y la garantía de los derechos humanos, expresados normativamente en la legislación de nuestro país, y que fueron / son producto de un proceso de tensiones que aún en la actualidad se siguen reivindicando en una coyuntura adversa y compleja, a partir de la recuperación de ciertos valores / disvalores fuertemente anclados en la discursividad social.

En el cierre del trabajo nos encontramos ante dos situaciones que nos interesa compartir para reflexionar: por un lado, ¿podemos adjudicar una responsabilidad exclusiva a los medios de comunicación por cómo crean la información activando este tipo de construcciones de sentidos sobre la inmigración latinoamericana o, en verdad, son parte de la discursividad social y los medios solo habilitan un espacio de participación en el que los comentadores / lectores expresan su posición?; por otro, ¿hasta qué punto los comentarios solo son la opinión de cada uno de los lectores en interdependencia con la «noticia» o en la actualidad, a partir de las plataformas digitales, pasan a formar parte de la información que aportan los medios en la enunciación de las problemáticas sociales actuales?

\section{Referencias}

ANGENOT, M. (2010). El discurso social. Los límites históricos de lo pensable y lo decible. Barcelona, España: Siglo veintiuno.

ARANCIBIA, C. y MONTECINOS, L. (2013). El blog de comentarios a textos de opinión en ciberperiódicos: un género en constante reconstrucción. Literatura y Lingüística, (28), 123-147. Recuperado de https://scielo.conicyt.cl/scielo.php?script=sci_arttext\&pid=S0716-58112013000200008

BAJTÍN, M. [1976] (1985). Estética de la creación verbal. Ciudad de México, México: Siglo veintiuno.

BENVENISTE, É. [1977] (2008). Problemas de lingüística general, tomo II. Buenos Aires, Argentina: Siglo veintiuno. 
CHARAUDEAU, P. (2003). El discurso de la información. La construcción del espejo social. Barcelona, España: Gedisa.

GALLO, D. (6 de septiembre de 2010). Hay mayoría de extranjeros en las villas. La Nación. Recuperado de https://www.lanacion.com.ar/1301797-hay-mayoria-de-extranjeros-enlas-villas

GRICE, P. (1991). «Lógica y conversación». En L. M. Valdés Villanueva (Ed.), La búsqueda del significado (pp. 511-530). Madrid, España: Tecnos.

LA NACIÓN (15 de julio de 2007). «LA NACION abre todas sus páginas a los lectores». Recuperado de https://www.lanacion.com.ar/925827-la-nacion-abre-todas-sus-paginasa-los-lectores

MANCERA RUEDA, A. y PANO ALAMÁN, A. (2013). El español coloquial en las redes sociales. Madrid, España: Arcos.

MOYA MUÑOZ, P. (2015). Los comentarios de los usuarios en la prensa digital: una propuesta para su estudio desde el discurso mediado por ordenador y los estudios periodísticos. Caracteres, 4(1), 178-199. Recuperado de http://revistacaracteres.net/revista/vol4n1mayo2015/comentarios-usuarios

NOBLÍA, M. V. (2015). Un pacto de mutua agresión: la negociación de la imagen y el rol de la audiencia en los diarios digitales. Textos en Proceso, 1(1), 16-49. Recuperado de http://oa.edice.org/index.php/tep/article/view/11/12

REYES, G. (1990). La pragmática Lingüística. El estudio del uso del lenguaje. Barcelona, España: Montesinos.

VALENTINO, A. y FINO, C. (2016) (Coords.). La información como discurso. Recorridos teóricos y pistas analíticas. La Plata, Argentina: EDULP. Recuperado de http://sedici.unlp.edu.ar/bitstream/handle/10915/46739/Documento_completo_.pdfPDFA.pdf?sequence=1 


\section{Notas}

1 El proyecto se denomina «El discurso de la información como objeto de estudio ¿Cómo, por qué y para qué analizar el discurso de la información?» (Cod. 11/P248) y se inscribe en el Centro de Investigación en Comunicación, Educación y Discurso (COMEDI), de la Facultad de Periodismo y Comunicación Social de la Universidad Nacional de La Plata. Es dirigido por Alejandra Valentino y codirigido por Claudia Fino.

2 En pos de la claridad en la exposición de este texto, enunciamos en cursiva cada uno de los comentarios analizados correspondientes al discurso periodístico digital referido con el objetivo de distinguirlos del análisis propiamente dicho. Esto incluye la decisión de no corregir las cuestiones de forma y de contenido en los comentarios: por ejemplo, la utilización de mayúsculas, que en el discurso digital se la asocia a un tono enfático, de voz elevada, entre otras características.

3 En la nota correspondiente a los comentarios que analizamos se dice: «Estos programas asistenciales son compatibles con otras ayudas entregadas por el gobierno nacional a las mismas personas» (La Nación, 6/9/2010, en línea).

4 Recordemos la figura del gaucho, para Faustino Sarmiento; la del indio, en el Martín Fierro de José Hernández; la del inmigrante, para Leopoldo Lugones; la del «monstruo», para Jorge Luis Borges y Adolfo Bioy Casares; la del «subversivo», para la última Dictadura cívico militar argentina; la «grasa militante», para el macrismo actual. 